\title{
Sonic Pipelines at the Seafloor
}

\author{
Lisa Y. $\operatorname{Han}^{1}$ a \\ ${ }^{1}$ English, Arizona State University, Tempe, Arizona, US \\ Keywords: sonar, environmental media, oil prospecting, seismic surveys \\ https://doi.org/10.1525/001c.21392
}

\begin{abstract}
How did the offshore oil industry develop the means to image the seafloor with photographic precision? What are the stakes of producing images through processes that simultaneously produce carcasses? This essay addresses these questions by charting the ambivalent history of reflection seismology from the 1940 s to the present day. In the postwar era, when offshore drilling was just emerging, companies like Union Oil, Shell Oil, Macco Corporation, and affiliated researchers were key actors in the development of offshore prospecting techniques. From wire sounding technologies like the soundfish to modern airgun surveys, the hunt for energy resources paved the way for high-resolution imaging of the ocean floor, despite devastating ecological casualties. Drawing from sound studies scholarship in addition to interviews and oceanographic records, this essay focuses on how petroleum surveys have affected the material space of their interventions. In particular, I theorize the survey as a distinct framework for knowledge that privileges comprehensive and continuous information feeds. I contend that the repeated bias toward frictionless signal in combination with discourses of energy security has obscured and even justified the harmful ecological impacts of reflection seismology on ocean environments. Ultimately, I argue that rather than starting with the visual abstractions of survey maps and seismic images, attention must be returned to the violent sonic "bangs" of surveying - a recurring event that is inseparable from the nonhuman and environmental agencies, casualties, and affects that co-constitute the mediamaking process.
\end{abstract}

It starts with a bang. In the late 1940s, World War II had just come to a close, and the United States was eagerly in the midst of a race for offshore oil. Many early prospecting efforts were beginning to occur in the Gulf of Mexico-a new frontier for large oil fields. But by this time, the offshore petroleum industry already had a foothold on the West Coast. Santa Barbara County, home to the earliest offshore oil rigs ever created since the 1890s, was already a focal point for the budding industry during this postwar pursuit of oil. By the mid-1940s, companies like Union Oil Company of California, Signal Oil, Shell Oil, and Macco Corporation were all experimenting with new techniques for offshore geophysical surveys in the Santa Barbara Channel (Rand 1957). Following this trend, from March 1948 to October 1948, Union Oil conducted seismograph surveys south of the city, suspending geophones and dynamite charges from surface floats four to six miles offshore as well as near the middle of the Santa Barbara Channel.

\footnotetext{
a Lisa Yin Han is an Assistant Professor of Film and Media Studies in the Department of English at Arizona State University. Her research is situated at the intersections of environmental media studies, media infrastructure studies, and science and technology studies. She has published her work in journals such as Configurations, Communication, Culture \& Critique, and Contraception. Lisa is currently working on a book entitled, Benthic Media: Underwater Technology and the Taming of the Seafloor.
} 


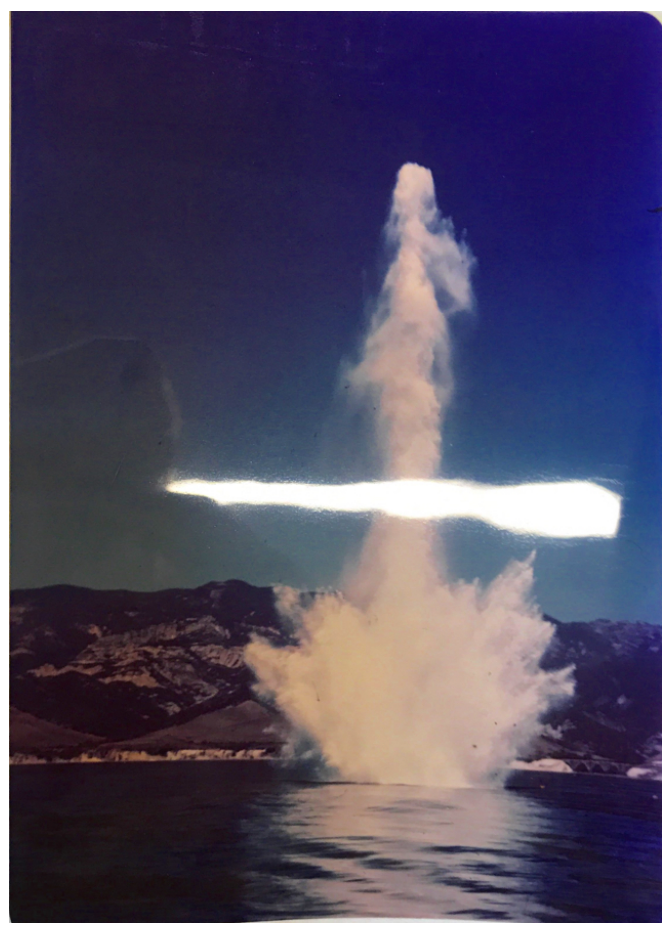

Figure 1: Dynamite blast during Marine Seismograph Survey by Union Oil Company of California, 1948.

William Whitehall Rand Papers, SBHC Mss 46, Department of Special Collections, UCSB Library, University of California, Santa Barbara.

The public reacted with outrage. Explosive bangs near the Santa Barbara shoreline led to protests and an official complaint from the county, which elaborated that "said blastings have been killing a great quantity of fish and other sea life, along said coastline, and have endangered the lives and property of the residents of said County and said blastings have further interrupted the peaceful enjoyment of the beaches and parks by the people of said County of Santa Barbara" (Resolution of the Board of Supervisors of the County of Santa Barbara, \#8242 1948). A resolution was subsequently passed, requesting that state agencies including the Fish and Game Commission of the State of California protect Santa Barbara's beaches from offshore bangs. A crosscomparison with 1948 archival documents from Union Oil reveals a more precise picture of how these surveys were deployed. The crews used jetted charges, or explosives buried ten to fifteen feet below the seafloor by water jets, in order to minimize fish kill. Yet even with 214 jet shots, the Union Oil report estimated that the weight of fish killed by the surveys during this time was roughly twenty-five tons (United Geophysical Company 1948, 14).

It is fitting, perhaps, that bangs occupy a space in our collective conscious that contains both the marking of death, as in the bangs of firearms, and the violent creation of life, as in the primordial bang itself, the bang that generated the universe - the big bang. In his analysis of wartime sound and listening, J. Martin Daughtry categorizes combat noises like bangs as "belliphonic" sound, sounds that stand opposed to reason (Daughtry 2014, 5, 33). These constitute Daughtry's "wartime acoustic sublime: the harsh euphoria of a loud close call 
with death" (Daughtry 2015, 36). Indeed, the materiality of bangs both big and small seems suited for the delineation of beginnings and endings. Frances Dyson calls the big bang "a sonic event rather than a sonic continuum... The 'bang' is a noise among an overall noisiness, an identifiable sonic 'thing' or 'event' or even 'object' that stands out, protrudes into materiality, and turns noise-the generalized hum that barely enters language as a category of the sensible-into sound" (Dyson 2014, 52). High amplitude sound waves are experienced as loud volumes that have a manifest materiality; they shock, they immobilize, and they penetrate into rock and earth. Bangs mark the physicality of acoustics and their boundary with the haptic realm. But what of the bangs that are a sonic continuum-the bangs where continuity is, in fact, the point?

In this essay, I trace the transformation of underwater bangs into a landscape of petroleum. Petroleum seismology is part of a growing realm of sonic communication in the ocean that includes the clicks and whistles of cetacean echolocation, submarine pings, booms, and other echoic sounds (Shiga 2013). ${ }^{1}$ But survey bangs are standout sounds within this taxonomy. Seismic surveys are accomplished by producing a series of high-energy acoustic blasts that hit the seafloor and echo back to a set of transducers, which translate sound waves into information about geological structures underneath the surface of the seafloor. ${ }^{2}$ To achieve adequate breadth, these bursts of sounds must be repeated hundreds of times, for days, weeks, and even months. A 1968 position paper on ocean exploration by the National Academy of Engineering distinguishes surveying from research by its "systematic collection programs on regional or world ocean scales" (ICOEES Typoe Task Group 1968). In a similar vein, the Merriam-Webster definition of a survey emphasizes both broadness and precision, citing comprehensive consideration and scrutiny through measurement and data collection ("Survey" n.d.). Petroleum surveys are meant to be exactly that-expansive yet highly methodical forms of data collection, used to find the anticlines or upfolds where oil occurs and can be extracted (Rand 1957, 2).

Problematizing the fetishes of technological precision and comprehensive coverage, I seek a return to the noisy, haptic, and explosive underpinnings of seismic surveys, critiquing the erasures of animal life and oceanic materiality that they engender. Beyond wonder-inducing gadgets and technics, beyond increasing efficacy and accuracy, I consider how deep-sea prospecting matters materially-how it affects the space of its interventions. As we mediate the seafloor, we also compose and delimit a space of reality that validates the presence of certain substances like petroleum, while eliminating others through the calculus of noise and interference. The most spectacular

\footnotetext{
1 Writing about the early development of sonar, John Shiga delineates a semiotic taxonomy of pings and echoes specific to underwater transmission and perception.

2 To hear a sample of a seismic airgun survey, see Ocean Conservation Research, “Seismic Airgun Surveys," http://ocr.org/portfolio/seismicairgun-surveys/.
} 
illustration of this process of selection and omission can be read in the controversies surrounding the ecological impacts of such surveys. The bodies of marine animals, which end up on beaches or, more frequently, rain down to the seafloor, are the forgotten companions to offshore oil-inextricably linked in their shared emergence, their alienation from the sea, and their circulation through our news worlds. These nonhuman experiences of acoustic mediation lead me to ask, What are the stakes of producing informatic bodies through vibrations that simultaneously produce carcasses?

While oil extraction has been interpreted in terms of its infrastructures, its cultural legacies, and its environmental implications, there has yet to be a theory of mediation that discusses oil extraction in relation to its preceding processes of imaging (cf. LeMenager 2014; Barney 2017; Szeman 2007). I start with the premise that audiovisual abstraction of the seafloor conditions the possibility for extraction by producing it as a space for the taking. From a nineteenth-century boom era defined by the bangs of exploration to a new age of offshore drilling, seismic surveys are material-discursive objects that have shaped and defined a culture around the geological structures that they seek to capture.

My argument mobilizes sound studies scholarship and sonic materialism to bear on the question of seafloor survey practices. Sound studies scholars like Karin Bijsterveld, Jonathan Sterne, Stefan Helmreich, and Axel Volmar have considered sonic epistemologies in terms of audile technique; they approach listening practices-from medical auscultation to the use of seismographs during the Cold War-as socially constructed, culturally encoded operations that inform and are informed by hegemonic perceptions of what counts as knowledge and credible evidence (Bijsterveld 2018; Sterne 2003; Helmreich 2008; Volmar 2013). That is to say, audile techniques contribute to the production of expert/lay boundaries and are bound up in the authorities of (Western) scientific knowledge production and notions of objectivity. In a similar vein, I am interested in the epistemology of offshore petroleum surveys, and approach these surveys as a technologically assisted, expert mode of listening and viewing. I also go a step further to contend that in their celebration as innovative observation technologies, these surveys displace awareness about the material impacts of mediation. In this sense, seismic imaging reproduces what Juliet Schor has called a materiality paradox: "a direct but unseen relationship between technology's symbolic power and the scale of its environmental impact” (Schor 2010, 40-41).

This essay starts with a media historiography of reflection seismology and its vexed relationship to bodies of oil and the bodies of cetaceans. First, I explore the binary of noise and signal underwater by examining a series of early seafloor survey technologies. This includes, in roughly chronological order, towed hydrophone devices like the soundfish, echo sounders, the continuous seismic profiler, and ocean-bottom seismographs. This historiographic exploration 


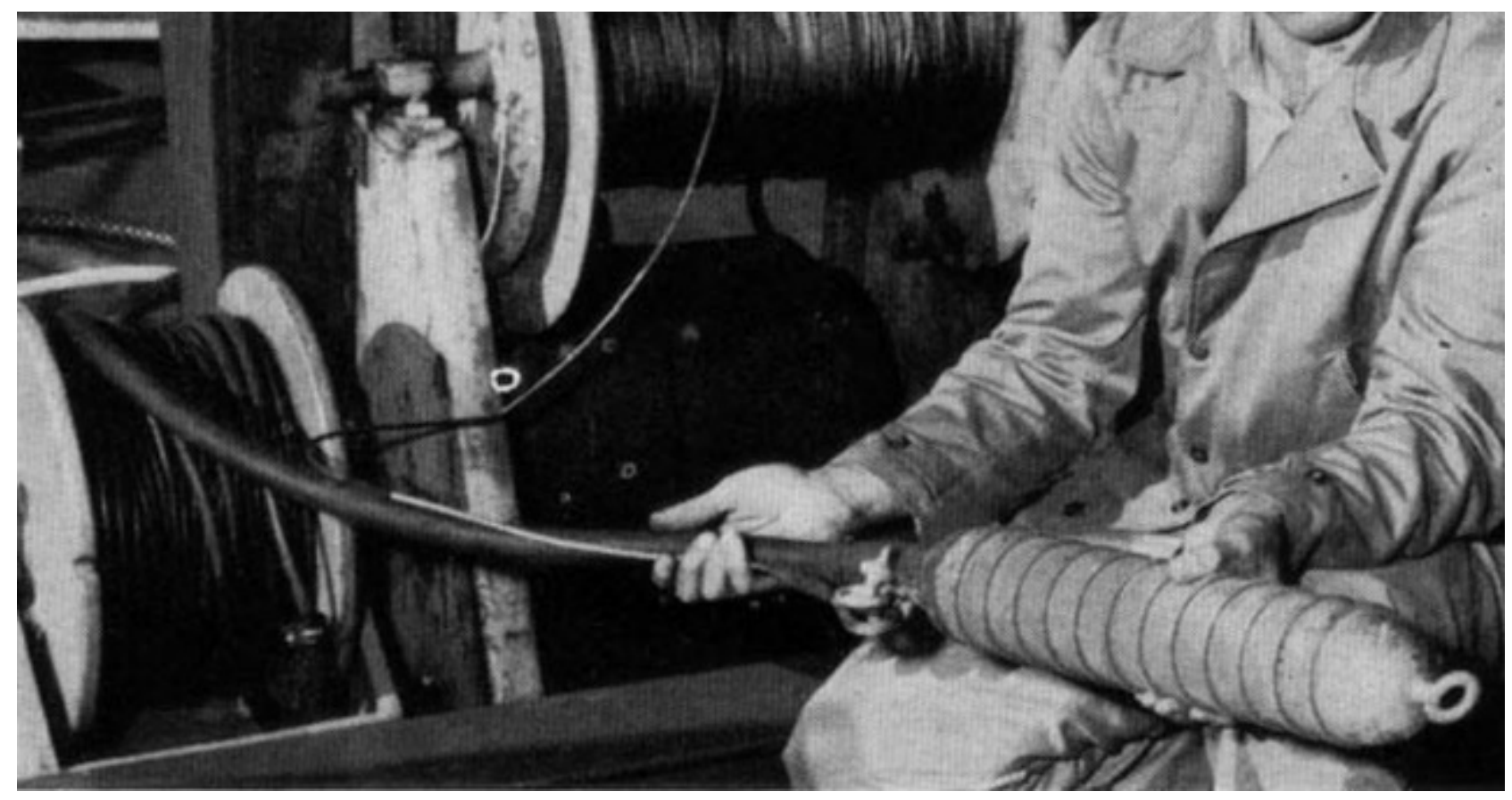

Figure 2: The soundfish, developed by the US Navy Electronics Laboratory for geophysical prospecting.

Photo: US Navy.

leads me to a discussion of the physical effects of sound imaging on marine life, attending to listening practices as impactful vibrational events in the ocean. In industrial attempts to facilitate signal and eliminate noise, there is a teleological pruning of sound throughout the history of oil surveying that, to me, forecloses other kinds of human relationships to ocean soundscapes. To the extent that sounding constructs communication feeds that cut out ocean ecologies, I describe these surveys as sonic pipelines, a first step in an extractive value chain that includes the creation of pipelines for oil.

\section{A Brief History of Offshore Prospecting Methods}

In the postwar era, oilmen were very concerned about the importance of finding domestic petroleum for the sake of national well-being. Spurred on by this sentiment, innovations in the exploration and discovery of onshore and offshore oil fields were reaching new heights. Although the earliest offshore oil prospecting consisted of physically collecting core samples, there was a movement to find techniques that could provide detailed and continuous, rather than intermittent, information about bottom sediments. Among the industrial survey methods used during the 1940s is a peculiar device called the soundfish, developed by the US Navy Electronics Laboratory for geophysical prospecting. The soundfish is a hybrid between a sampler and a sounder, created specifically with the aim of determining seafloor composition. It consisted of a hydrophone encased in a metal container, which could be dragged along the bottom of the seafloor. Frictional noises from the scraping of the metal cylinder on the bottom would then be picked up by the hydrophone and sent to an amplifier on the towing vessel, providing continuous 
information about the seabed. Researchers explain, "Rock makes continuous loud bongs or clangs, sand makes a heavy scraping or rasping noise, and mud makes a quiet swishing noise...it is necessary for the observer to train his ear by listening while the equipment is dragged at constant speed over known types of bottom, as determined by grab sampling" (LaFond, Dietz, and Knauss 1950, 108). The soundfish assumed a subject position in which the oceanographer was the ideal ear, responsible for filtering and interpreting constant streams of sensory information about the seafloor.

Variations of this method with simpler equipment have also been used concurrently, such as the dragging of a hollow metal pipe attached to a wire with an audio amplifier and a microphone at the top. As the navy researchers note, "Some information can even be obtained by listening with the ear near the wire and by feeling the wire with one's fingers. The nature of the tugging and jerking on the wire as well as the noises transmitted up the wire gives some information concerning the bottom character" (LaFond, Dietz, and Knauss 1950, 110). This mode of listening and feeling is perhaps striking for its focus on somatosensory perception, which seems to subsume audition as a sensing paradigm. Hydrophones in this case act as a proxy for human fingertips, providing detailed transmissions of noise through a highly sensory mode of interpretation.

However, for the decades when wire sounding technologies dominated, depth remained a highly ambiguous, terrifying space for hydrographers and other ocean researchers. Take, for instance, an account by the founding director of Woods Hole Oceanographic Institution, Columbus O’Donnell Iselin. Writing on equipment developed by the WHOI in 1932, Iselin characterizes ocean life as interference:

Unforeseen things are constantly hampering the work of each oceanographic expedition. For example, there are several kinds of marine animals which become wound around the hydrographic wire and stop the messengers... If the submarine "devils" are not interfering with the work, the "devils" of stormy weather are very apt to seize the opportunity to persecute the sleepy oceanographer. (Iselin 1932, 258)

Ostensibly, Iselin is referring to animals such as sea turtles, seals, and dolphins - the same kinds of creatures marked as at risk of being entangled in fishing gear and debris (NOAA Fisheries 2017). Iselin's flippant characterization of such creatures as "submarine 'devils" lessens the blow of the cruelty of entanglement, as it reduces both ocean and animal life into mere obstructions to the development of underwater communication and imaging. Famed oceanographers like Iselin helped to further refigure acoustic transmission in terms of targeting and accuracy through the mathematical 
elimination of aquatic obtrusions and ocean "noise" (Shiga 2013, 367-368). In this equation, the ocean and its animals were increasingly conceptualized as forms of interference.

For oceanographers like Iselin, the requirement of a mechanical connection to the bottom with traditional wire sounding techniques and devices like the soundfish was a burden that exacerbated unwanted connections to whatever was down there, demonstrating an underlying desire for observation at a distance. Wireless sounding was an antidote to fears of the deep. When echobased depth sounding finally appeared after the Titanic disaster, it was hailed as "a radical and brilliant step in man's mastery of the sea," emphasizing both the anxiety around the seafloor as an alien, nonhuman space and a desire to control it from a distance (Submarine Signal Company 1932).

The first echo sounders were developed concurrently by Reginald Fessenden and Alexander Behm in the early 1900s. The Fessenden oscillator, which was based on microphone technology and looked much like a loudspeaker, was a transducer capable of both generating sound and receiving it. Comprising an oscillating electric motor-generator encased by an electromagnet, the device produced a broad beam that sounded much like a dial tone and could travel up to thirty-one miles (Blake 1914, 1569; Dineen 2020). A telephone receiver on the ship would then enable an operator aboard the ship to listen to the signaling apparatus (Blake 1914, 1569). Subsequent echo-sounding technologies aimed to elevate signals and reduce noise, cementing a perceived need to manage the deep sea's unruly character. For sonar-based techniques, unruly noise could refer to things like environmental noise (wind, traffic, marine animals), intrinsic noise (electronic or swell noise specific to the tools being used), and reverberations, as well as "statics," or variable surface conditions that could obscure or change time measurements for the reflections, a crucial element in producing accurate images (Dragoset 2005, S48).

The answer to noise, as it so happens, was the production of more noise. The ocean is a sonic world. In water, sound travels four times faster than in air and, unlike sunlight, reaches into great oceanic depths. Furthermore, extreme bursts of acoustic energy have the ability to travel kilometers from a source and penetrate far into the seafloor. Echo sounders are high-frequency devices that are limited in their ability to retrieve information about the subbottom (below the seabed). By contrast, higher energy bursts allow surveyors to more accurately characterize geological structures and facilitate the clarity of information transmission. As a result, wartime developments led to the appropriation of weapons themselves for the purposes of underwater communication. That is, explosives, from dynamite to substances like pentaerythritol tetranitrate (used by the Germans in World War I), were and continue to be an important component of oceanographic surveys. 
Explosion seismology was popularized by physicist Maurice Ewing, who used TNT to study the continental shelf aboard the US Coast and Geodetic Survey ship Oceanographer (Lawrence 2002, loc 1535 of 3147). Established in 1807 as the first civilian scientific agency, the USCGS is the organization responsible for surveying the US coastline and creating nautical charts for the benefit of maritime safety. After Ewing's success in revealing geological characteristics beneath the ocean floor, however, reflection seismology grew to become a proven tool for the location of marine hydrocarbons. Dynamite was the original seismic source for surveys because it yielded strong reflection signals and was relatively mobile and compact. But in water, dynamite also had the drawback of producing noisy bubbles of gases, which restricted surveyors to using the explosives in shallow water (farther away from the target) so as to minimize the rise of bubbles. During the postwar era, these and other limitations led researchers toward alternatives to black powder as a source of explosion (Jakosky et al. 1956). Safety was perhaps one of the concerns; in 1957 an attempt by oceanographers aboard the Somersworth to detonate half-pound charges for Mark 3A offensive grenades resulted in catastrophe, killing three people on deck and injuring another four. The Somersworth disaster brought to light the dangers of using military explosives as signal sources, particularly without a demolitions expert (Westervelt 1957).

Oceanographers saw a need for more control, "a practical, lightweight, lowfrequency, high-intensity sound source, capable of being lowered to actuate at great depths, one which is unaffected by pressure" (O'Keefe 1960). This goal was eventually accomplished under the watchful eyes (and ears) of oceanographer John Brackett Hersey. A student of explosions pioneer Ewing both before and during the war, Hersey had a background in petroleum exploration, having initially worked with a seismic exploration crew for Phillips Petroleum (Geological Society of America 1993). Hersey was later hired to run an underwater acoustics program for WHOI under Iselin, the institution's director. He is primarily remembered as a champion of towed instruments, which required sound sources with a greater degree of control. Hersey coupled these newer explosive sources with towed hydrophone techniques to create the continuous seismic profiler (CSP), a widely used technique that consisted of the repetition of acoustic pulses several times per minute. This introduced a time-based understanding of resolution, in which high resolution equates to the temporal length of the seismic signal (Leenhardt 2015). The idea behind the rapid-fire CSP was to create a subbottom reflection that would approach a continuous graphic profile, an update on the continuity that was first available with towed hydrophone technologies like the soundfish. By the late 1960s, CSP techniques were widely deployed for offshore oil exploration, and they were used almost as universally as echo sounding. The success of CSP ultimately revolved around increasing signal-to-noise ratios and using powerful sources. That is, the development of controlled acoustic sources beyond traditional explosives set the stage for the production of continuous data. 


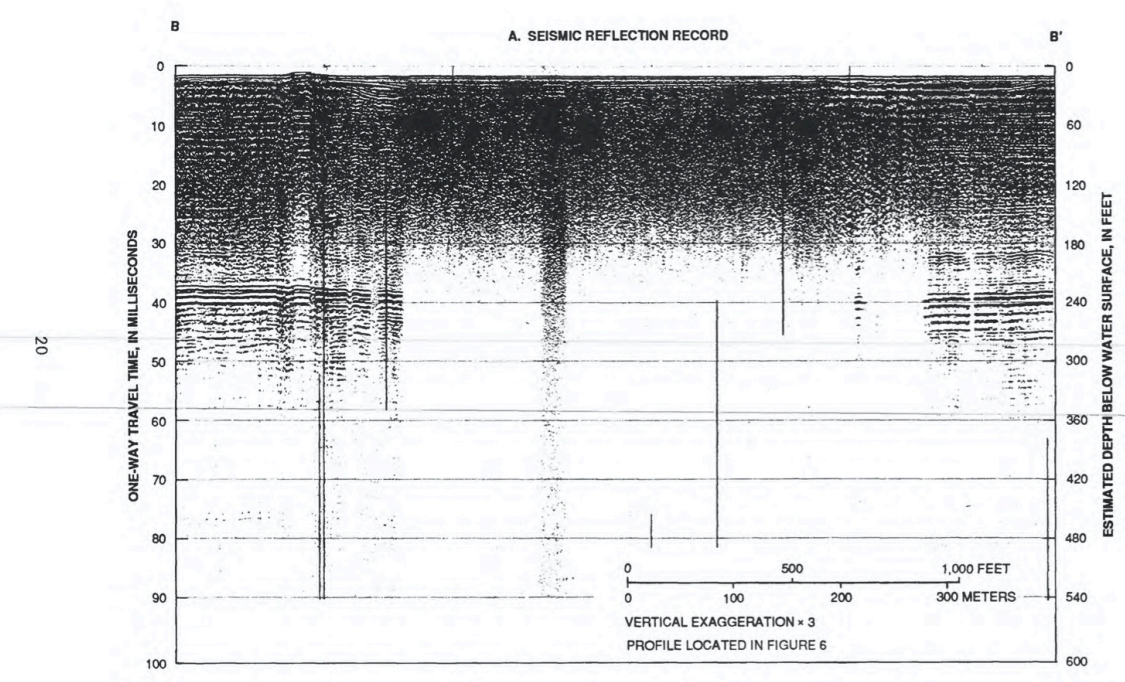

Figure 3: CSP profile at a well site in New River, Camp Lejeune, North Carolina, alongside stratigraphic record. Photo by US Geological Survey, 1990.

Some of these alternative sound sources were electrical, creating discharge from spark plugs to generate high-energy acoustic signals with broad sound spectrums. These energy pulses could "behave somewhat like an explosion, though much weaker" (Hersey 1965, 22-23). Parallel developments also emerged from the laboratories of Socony Mobil Company and Lamont Geological Observatory of Columbia University, leading to world-circling profiles (Hersey 1965, 23). Perhaps most significantly, in the 1970s, Lamont and manufacturers Bolt Technologies and Texas Instruments pioneered the use of air guns, which could create blasts of pressurized air as a sound source. Sometimes, CSP techniques involved the simultaneous use of two different sources, such as combining air guns with underwater sparks (Knott and Bunce $1968,634)$. Today, air guns are typically towed from survey ships and arranged in a square array below the waterline. Streamer surveys can be done either by a single ship along one vector above the target zone or by a ship traversing multiple vectors above the target zone.

Air gun surveys typically fire their sources five or six times a minute at 200-240 decibels. When translated from an aqueous context to air, this is the equivalent of 140-180 decibels, which approaches the threshold for human pain and long-term hearing damage. While billed as "more environmentally friendly than explosives" (Aminzadeh and Dasgupta 2013, 54), modern air gun surveys that release blasts of compressed air still create pressure waves that can penetrate several hundred kilometers into the ocean floor and have a wide range of negative impacts on whales, fish, and invertebrates (Weilgart 2013; 


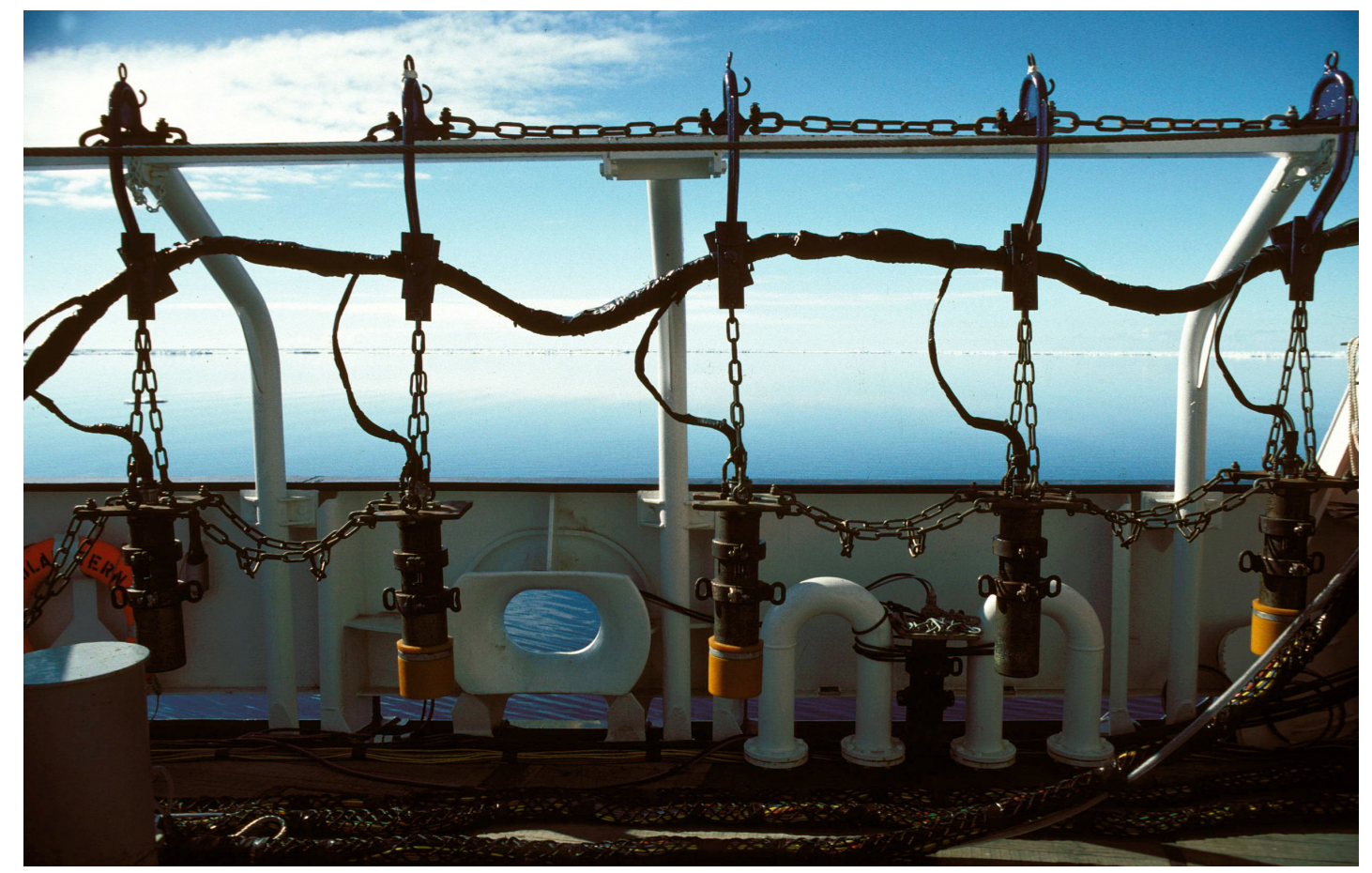

Figure 4: Air gun array on research vessel, used for seismic profiles.

Photo courtesy of Hannah Grobe, 2008 (cc).

Conservation and Development Problem Solving Team 2000; Natural Resources Defense Council 2010). By the mid-1970s, more than 50 percent of marine seismic surveys relied on air guns (Dragoset 2005, S54).

\section{Sound clip. Air gun and echo sounders}

Courtesy of Ocean Conservation Research, http://ocr.org/sounds/seismic-airgun-surveys/.

Driven primarily by the anxiety about petroleum and hard mineral interests, Hersey and his colleagues in underwater sound thus had a distinctly extractive understanding of the seafloor and a practical understanding of the precarious institutional funding for marine science. In a 1971 speech, Hersey stressed the importance of industry in funding marine science:

It is worth reminding ourselves that both petroleum and hard mineral interests are already moving their experimental operations into the deep ocean. Various departments of the federal government need deep ocean capabilities. . If my figures are not woefully dated petroleum investment at sea at all depths is a few billion per year, and the federal government spends slightly over half a billion on what is classed as marine science... Each must make his own counsel regarding this influence, but there seems little doubt that the wealth and the understanding of the oceans will need to be exploited increasingly in years to come. (Hersey 1971) 
With a foot in both the scientific and the industrial worlds, Hersey saw the link between surveying and drilling. He also understood that while air gun arrays towed from surface ships can reveal the basics of the uppermost crustal layers, they are often still noisy and low in resolution, generating long wave fronts that limit the ability to determine small structural changes, and subjecting the signal to current distortions. This became a problem with deepwater drilling and the discovery of oil reserves inaccessible in shallow water. Prospectors needed more detailed, accurate information at greater depths. Hersey thus realized a need for bottom profiles with "near-photographic detail" beyond what existing echo sounders, which he thought were "meager and rather clumsy," could do.

In the wake of the growing deepwater drilling industry, the mid-1970s saw the development of ocean-bottom seismographs ("IPOD Site Survey Criteria: Multichannel Seismic Surveys of IPOD Sites” 1975). High-energy explosives release more energy through intramolecular decomposition and are usually detonated by a combination of heat and a shock wave (this is how dynamite, or nitroglycerine, is detonated) (Roberts, n.d.). Bottom seismographs place both the explosives and the receivers (seismographs) on the seafloor instead of towing them behind a ship, offering more direct forms of penetration with precise energy points (Dragoset 2005, S67). They retrieve, in turn, more accurate wave velocities within thick sediment columns (Koelsch et al. 1986, 345-346). Unlike the CSP method, ocean-bottom seismographs capture the complexity of the crust and upper mantle, which makes them valuable additives to initial CSP surveys for the petroleum industry. Ocean-bottom seismographs have also been used to observe earthquakes (entailing long-term deployment and observation) in addition to registering data from artificial sources. With the aid of these devices, by 1975 deepwater drilling was in full swing, exploiting depths of five hundred to a thousand feet or more (definitions vary).

Bottom technologies continued to grow in their scale and sophistication as drilling interests moved toward deeper waters like those in the Gulf (Tursi 2015). Jim Broda, a researcher at WHOI, led a project in 1990 called the Near Ocean Bottom Explosive Launcher (NOBEL), the first imaging system to detonate multiple high-explosive charges at the bottom. I caught up with Broda at WHOI, where he explained his experience with bottom seismographs in relation to his own invention. NOBEL started out essentially as a bomb strapped with 1,200 pounds of TNT and thrown into the ocean. Later, TNT was replaced with high-energy, warhead-grade energetic materials, including pentolite and other US Navy explosives. Broda remarked, "The results we got were extraordinary.... It'd be like, I used to study the moon with binoculars in a lounge chair in my backyard and now I'm standing there. That's the leap in resolution" (Broda, correspondence with author, June 25, 2018). Broda's use of a visual metaphor to describe this effect highlights the way in which sonic information is rendered and understood culturally as akin to visual media 


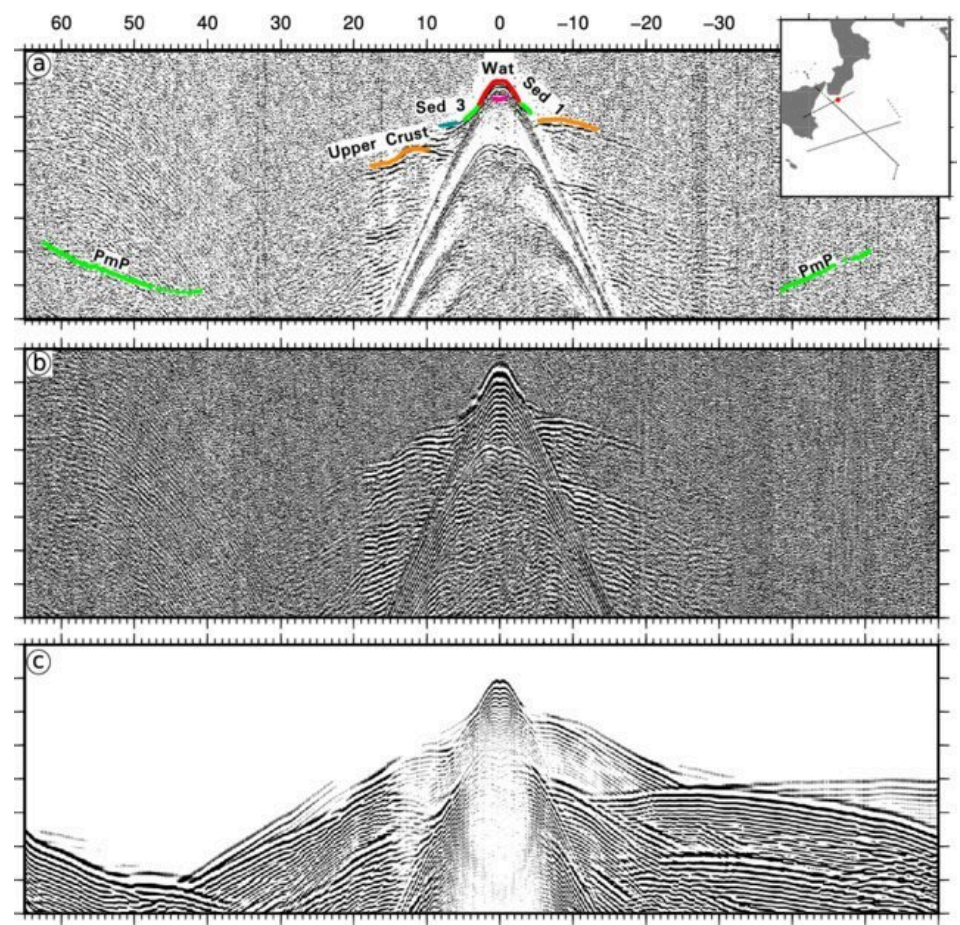

Figure 5: An example of data from an ocean-bottom seismograph in the Ionian Sea: (a) annotated image; (b) raw seismic section; (c) after calculations using velocity model.

Image via Dellong et al. 2018.

forms. Marine geologists talk about sedimentary formations in terms of resolution and clarity, equating higher energy release to higher image fidelity. The bigger the bomb, the better the picture.

\section{The Belliphonic Bang}

In a sonic pipeline, fluid collection of acoustic signals preempts and mirrors the production of resource pipelines. Exploitation and extraction of seafloor resources have produced a link between the pursuit of knowledge and the pursuit of economic resources, further justifying the material elision and ultimately sacrifice of those marine inhabitants that live in between this production of signal and noise. Drilling becomes a form of knowing, and knowing itself a paring down of life (American Petroleum Institute 2015, 1, 7).

There has been important scholarship in acoustic ecology, anthropology, and history that has pushed back against the noise/signal binary as a one-way transmissive model, finding ways of validating noise itself as a cultural object. ${ }^{3}$ For instance, philosopher Michel Serres discusses noise in terms of the figure of the parasite, drawing attention to the vitality of process, propagation, and mediation: "in the beginning was the noise" (Serres 1982, 13). Building on these works, we can also refuse this division of ocean into signal and noise

3 Emily Thompson, for instance, talks about historical periods in which sonic culture is defined by noisy din, while Brian Larkin discusses the differential and socially layered filtering of noise and signal within urban soundscapes in Nigeria (Thompson 2004; Larkin 2008). 


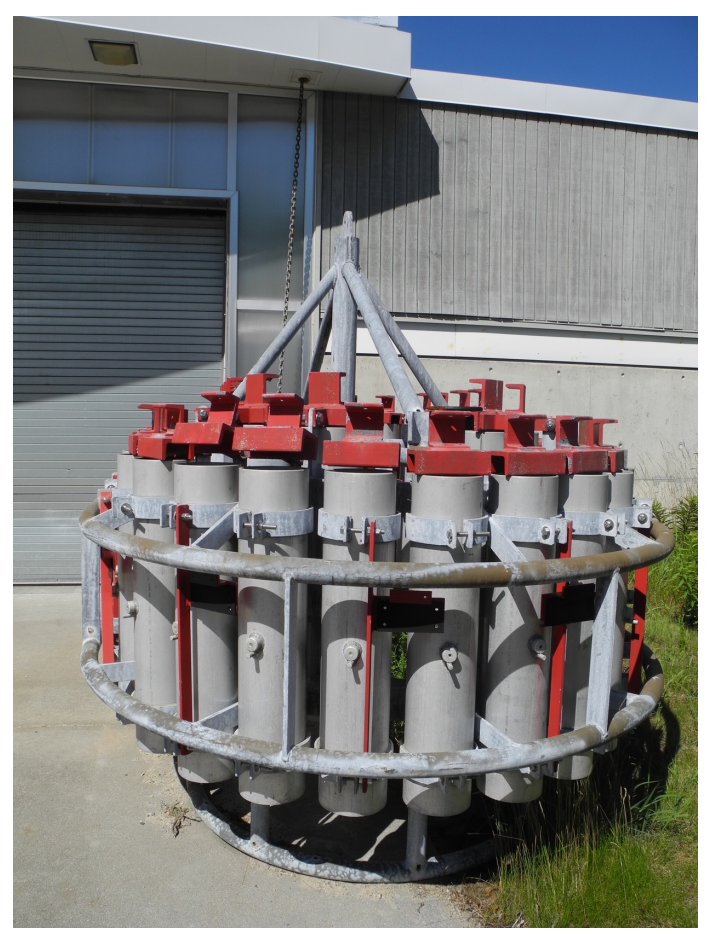

Figure 6: The Near Ocean Bottom Explosive Launcher (NOBEL).

Photo by the author, July 25, 2018.

by attending to the bang; it is an object that is both noise and signal, that prompts immersive feeling while simultaneously communicating information. And bangs, importantly, lead us to nonhuman formations, and the differential experience of noise in the ocean by its inhabitants.

Cetaceans perceive the world through large auditory organs that can determine sizes, shapes, speeds, and textures of objects. Unlike human beings, whales hear just as well at depth as they do on the surface (Yamato and Pyenson 2015). The principle of hearing by feel that characterizes the soundfish can also describe seismographs, which use acoustic blasts to "touch" the seafloor, as well as natural experiences of sound among cetaceans. This is a hapticity that fuses not the eye and the hand, as Gilles Deleuze and Felix Guattari would say, but the ear and the hand; it is the discovery of touching within the hearing function (Deleuze and Guattari 1990). The fusion of haptics with sonics in the hearing function is perhaps more easily grasped in the concept of something like bone conduction, in which vibrations trigger the inner ear via vibrations in the jaw. Cetaceans, who navigate, hunt, and form social groupings primarily through echolocation, hear in a haptic way that resembles bone conduction. In fact, toothed whales do not hear through an eardrum and transduction through the middle ear like humans do, but rather through the fatty tissues in their head and jaws, which connect sound vibrations to their inner ear via an acoustic funnel (Yamato and Pyenson 2015). Spatial distance between the source and reception of a haptic sound, as Deleuze and Guattari and Colin Milburn explain, does not act to separate but rather serves as a medium of passage (see Milburn 2008, 85). 
Speaking to these physical processes of hearing, sound theorists such as Steve Goodman and Daughtry position sound within the framework of vibrations, accounting for aspects of sound that exceed the disembodied ideal ear. To them, vibrations instead push us to consider sound as a phenomena that is both haptic, sonic, and affective. As Goodman puts it, "sonic culture, thus situated, renders the urban audiosocial as a system of speeds and channels, dense pressure packets, vortices of attraction, basins of acoustic immersion and abrasion, vibratory and turbulent: a whole cartography of sonic force" (Goodman 2010, 9). The materiality of noise can thus orient its readers toward the intimate mediatory capacities of water, land, and animals.

Impacts of anthropogenic noise on more charismatic creatures like cetaceans have been very well documented. So it is with a consideration of whale hearing, and with the deafening of marine inhabitants, that we can revisit sound as a haptic force that spills over the bounds of information and signal into nausea, overload, and noise. According to a 2009 study by a Scripps Institution of Oceanography researcher, ambient anthropogenic noise has been doubling in intensity every decade for more than sixty years (Hildebrand 2009, 14). In 2012 scientists measuring ambient noise levels and tracking the calls of North Atlantic right whales have estimated that right whales have lost 63-67 percent of their traditional communication space due to man-made noise (Hatch et al. 2012). These sounds interfere with aquatic life-forms that depend on sound to find food, to mate, and to escape predators.

Blue whales, fin whales, gray whales, right whales, and humpbacks sing complex, locally specific songs to navigate and communicate with one another in a manner resembling dialects, constituting, as Margaret Grebowicz notes, "the largest communication network for any animals, with the exception of humans" (Grebowicz 2017, Kindle location 107 of 2251). Additional noise in the ocean from shipping and sonar impacts migration, mating, and other social behaviors (NOAA National Marine Sanctuaries 2016). Many whale breeding grounds, for instance, including those of humpbacks and right whales, occur in the warm coastal waters of the South Pacific (Cascadia Research Collective 2019). Their calves, however, are easily stimulated by noise, and thus increases in noise around these coastal areas mean that key sanctuaries are being lost. The disruption to these nonhuman networks of communication puts the anthropocentric characterization of surveys in sharp relief, revealing the many ways in which our ambition to clarify one type of communication signal can interfere with the signals of others.

Bangs also raise concerns about the thresholds at which acoustic vibrations become a violent physical force. In close proximity, the effects of these manmade sounds are extreme. The physical shock from seismic blasting travels faster than the acoustic velocity of an explosive (Keevin and Hempen 1997, 23). This is perhaps where the metaphor of the sonic pipeline encounters its limits - while prospectors visualize direct vectors of sonic information from 
the seafloor to the surface in diagrams and graphs, the energy produced by seismic surveys is not contained but rather propagates radially through the environment. Animals near a blast can experience immediate hearing impairment, while fish eggs and larvae can be killed by the explosive pulses. Recently, a 2017 study on air guns showed adverse impacts to zooplankton, causing two- to threefold increases in dead adult and larval zooplankton and catastrophic death to larval krill in the air gun passage (McCauley et al. 2017, 1). Zooplankton are crucial players in the ocean food chain.

Mitigation and regulation of sound in the ocean has often been a matter of creating cartographic sound maps of the ocean to limit sonar use in abstract spatial terms. ${ }^{4}$ Current seismic activities are made to stop when whales are spotted fifty-six miles from the blast site, but this means little in an environment where sound can travel as far as two thousand miles. As whale researcher Scott Kraus puts it, mitigation strategies for seismic activities are "a little bit of a lipstick on a pig. That is to say they will prevent immediate mortality if a whale gets so close that it's going to get blown up" (quoted in Lemoult 2019). Other reactions fall short of banning sonic technologies and instead recommend case by case consideration and mitigation strategies. A 2002 report by the Scientific Committee on Antarctic Research (SCAR) Ad Hoc Group on the "Impact of Marine Acoustic Technology on the Antarctic Environment" recommends, for instance, uses of minimum source level, careful laying of survey lines, avoidance of repeat surveying of an area in consecutive years, and the use of "'soft starts' whereby power is increased gradually over periods of 20 minutes or more" (O’Brien, Berrow, and Wall $2005,5)$. The idea of soft starts is one that resembles older techniques and operates like a warning to animals. In their 1997 report on how to mitigate environmental effects of underwater blasts, for instance, engineers Thomas Keevin and Gregory Hempen similarly recommend a combination of helicopter aerial surveys and smaller blasts from shell crackers or "seal bombs," which would ideally "scare' marine mammals from the blast zone prior to detonating the large explosion” (Keevin and Hempen 1997, 74).

The portrayal of mild sonic bangs as a form of risk mediation fits neatly into the calculus of extraction, centering the perspective of a knowledge-seeking human researcher as the ideal listener or ideal ear, responsible for discerning noise from signal and minimizing external impact. It largely ignores or deems negligible the production of nonhuman affects like fear, anxiety, and confusion. Evidence of such affective changes abound: whales change their vocal behaviors around seismic surveys, either calling more frequently or ending their singing around operations (Di Iorio and Clark 2010, 51-54). Meanwhile, white whales were

4 As Amy Propen discusses, cartographic representations of the sea are treated as synonymous with the sea itself, lending the ocean to a form of prehensive violence in which destruction is justified through its containment in abstract spatial and temporal terms (Propen 2012, 165-167). 
found with increased norepinephrine, epinephrine, and dopamine levels after seismic air gun exposures, while bottlenose dolphins have shown increases in aldosterone, indicating stress (Peng, Zhao, and Liu 2015).

The oil and gas industry continues to avoid acknowledgment of the harmful effects of seismic surveillance in publicly available press releases, websites, and reports. Groups like the Petroleum Exploration and Production Association of New Zealand and the American Petroleum Institute issue blanket denials, insisting that surveying, the "first step" in oil extraction, is below a threshold of harm to the environment. To underscore its innocuous nature, API, for instance, calls these imaging processes "ultrasounds of the earth," infusing them with a maternalistic imaginary where oil, like the fetus, is validated as a cultural object through mediation.

Such reassurances are often accompanied by an insistence that whatever is being done to the ocean by the industry is essential to the well-being of nations. For instance, in its justification of offshore oil, the API states, "in order to ensure our energy security and create economic growth it is vital that we take advantage of all our energy resources, including those safely developed in American waters" (American Petroleum Institute, n.d.). This is what Imre Szeman calls the logic of "strategic realism": "At the heart of strategic realism stands the blunt need for nations to protect themselves from energy disruptions by securing and maintaining steady and predictable access to oil" (Szeman 2007, 6).

As land-based resources shrink, oceanic surveys and resource prospecting are becoming central to the maintenance of an industrialized and now digitized society. Just last year, the Trump administration approved seismic air gun surveys in the Atlantic by oil and gas companies, jeopardizing efforts to protect endangered species like the North Atlantic right whale (Natural Resources Defense Council 2018). Stateside, the Natural Resources Defense Council (NRDC) has been leading the battle to protect whales from seismic blasting through a series of lawsuits, while using social media to create public awareness around the issue. Other environmental groups such as Oceana, the Center for Biological Diversity, the Southern Environmental Law Center, the Coastal Conservation League, and more have joined the fight to block seismic permits for oil companies on the basis of violations of the Marine Mammal Protection Act, the Endangered Species Act, and the National Environmental Policy Act (Natural Resources Defense Council 2019). Coastal communities in areas such as Cape May, New Jersey, have also drawn bipartisan crowds protesting the Trump administration's expansion of oil and gas surveying in the Atlantic (Rosenberg 2019). Now, more than ever, is the time to rejoin our resources and our technologies to their oceanic substrates and ecologies. 


\section{Conclusion}

Standing on the shore, stepping between the bits of tar speckling the beaches by UC Santa Barbara, a visitor could perceive a casual, intuitive connection to oil here. From the shallows, our ways of seeing oil, feeling oil, and smelling oil connect us to extractive industries on a bodily level. But on the hearing and sounding level, that same kind of embodied intimacy with oil industries remains absent. Seismic blasting is not the sort of thing people complain about on a regular basis-stories of seismic blasting disturbing the peace for human beachgoers are few. But they are becoming an increasingly common experience for cetacean communities. As anthropogenic noise in the ocean worsens and offshore oil extraction moves to deeper and more remote waters, focusing on the easy, accessible kind of environmental awareness located in sporadic and spectacular events like oil spills is not enough.

Although we may be situated at a distance, recognizing sonic mediation as both material and discursive grounds human responsibility in a world that exceeds our own values and perceptual limits. In this essay, I have tried to encounter the bangs of petroleum surveys as a haptic force, offering a perspective on the relationship between hearing and feeling. Thinking about the excesses of sound in an underwater environment forces us to recognize mediation as itself extractive. As Tim Ingold has stated, "the ways of acting in the environment are also ways of perceiving it" (Ingold 2002, 7). In underwater environments, the uncertainty principle is also itself a certainty-the very act of observation impacts that which is being observed. Bangs do not just mark beginnings and ends, they mark the middles too.

\section{Transparency Statement}

This essay is derived from the author's dissertation project. It does not contain any competing interests.

Submitted: June 02, 2020 PST, Accepted: March 04, 2021 PST

This is an open-access article distributed under the terms of the Creative Commons Attribution 4.0 International License (CCBY-4.0). View this license's legal deed at http://creativecommons.org/licenses/ by/4.0 and legal code at http://creativecommons.org/licenses/by/4.0/legalcode for more information. 


\section{REFERENCES}

American Petroleum Institute. 2015. “Offshore Access to Oil and Natural Gas Resources.” In February 2015, American Petroleum Institute Report. http://www.api.org/ /media/files/oil-andnatural-gas/offshore/offshoreaccess-primer-lores.pdf.

- - - n.d. "The Offshore Energy We Need." https://www.api.org/oil-and-natural-gas/energyprimers/offshore/the-offshore-energy-we-need.

Aminzadeh, Fred, and Shivaji N. Dasgupta. 2013. Geophysics for Petroleum Engineers. Newnes.

Barney, Darin. 2017. “Pipelines.” In Fueling Culture: Politics, History, Energy, edited by Imre Szeman, Jennifer Wenzel, and Patsy Yaeger, 267-70. Fordham University.

Bijsterveld, Karin. 2018. Sonic Skills: Listening for Knowledge in Science, Medicine and Engineering (1920s-Present). United Kingdom: Palgrave Macmillan UK.

Blake, R. F. 1914. "Submarine Signaling: The Protection of Shipping by a Wall of Sound and Other Uses of the Submarine Telegraph Oscillator.” Proceedings of the American Institute of Electrical Engineers 33 (10): 1569-81. https://doi.org/10.1109/paiee.1914.6661262.

Cascadia Research Collective. 2019. "Summer Feeding Areas, Winter Feeding Areas and Migration.” 2019. http://www.cascadiaresearch.org/splash-structure-populations-levels-abundance-and-statushumpback-whales-north-pacific/summer.

Conservation and Development Problem Solving Team. 2000. "Anthropogenic Noise in the Marine Environment." The National Oceanic and Atmospheric Administration and the Marine Conservation Biology Institute. http://sanctuaries.noaa.gov/management/pdfs/anthro_noise.pdf.

Daughtry, J. Martin. 2014. “Thanatosonics: Ontologies of Acoustic Violence.” SocialText 32 (2): $25-51$.

-_- 2015. Listening to War: Sound, Music, Trauma, and Survival in Wartime Iraq. Oxford: Oxford University Press. https://doi.org/10.1093/acprof:oso/9780199361496.001.0001.

Deleuze, Gilles, and Félix Guattari. 1990. “The Eye and the Hand.” In The Logic of Sense. New York: Columbia University Press.

Dellong, David, Frauke Klingelhoefer, Heidrun Kopp, David Graindorge, Lucia Margheriti, Milena Moretti, Shane Murphy, and Marc-Andre Gutscher. 2018. "Crustal Structure of the Ionian Basin and Eastern Sicily Margin: Results from a Wide-Angle Seismic Survey.” Journal of Geophysical Research: Solid Earth 123 (3): 2090-2114. https://doi.org/10.1002/2017jb015312.

Di Iorio, Lucia, and Christopher W. Clark. 2010. "Exposure to Seismic Survey Alters Blue Whale Acoustic Communication.” Biology Letters 6 (1): 51-54. https://doi.org/10.1098/rsbl.2009.0651.

Dineen, James. 2020. "Reginald Fessenden and the Invention of Sonar." Distillations, Science History Institute. https://www.sciencehistory.org/distillations/reginald-fessenden-and-the-invention-ofsonar.

Dragoset, Bill. 2005. “A Historical Reflection on Reflections.” The Leading Edge 24 (s1): s48. https://doi.org/10.1190/1.2112392.

Dyson, Frances. 2014. The Tone of Our Times: Sound, Sense, Economy, and Ecology. Cambridge: The MIT Press. https://doi.org/10.7551/mitpress/8427.001.0001.

Geological Society of America. 1993. "Memorial to John Brackett Hersey, 1913-1992.” http://www.geosociety.org/documents/gsa/memorials/v24/Hersey-JB.pdf.

Goodman, Steve. 2010. Sonic Warfare: Sound, Affect, and the Ecology of Fear. Cambridge, MA: The MIT Press. https://doi.org/10.7551/mitpress/7999.001.0001.

Grebowicz, Margret. 2017. Whale Song (Object Lessons). Kindle Edition. New York: Bloomsbury Publishing. https://doi.org/10.5040/9781501329289. 
Hatch, Leila T., Christopher W. Clark, Sofie M. Van Parijs, Adam S. Frankel, and Dimitri W. Ponirakis. 2012. "Quantifying Loss of Acoustic Communication Space for Right Whales in and around a U.S. National Marine Sanctuary.” Conservation Biology 26 (6): 983-94. https://doi.org/ 10.1111/j.1523-1739.2012.01908.x.

Helmreich, Stefan. 2008. "An Anthropologist Underwater: Immersive Soundscapes, Submarine Cyborgs, and Transductive Ethnography." American Ethnologist 34 (4): 621-41. https://doi.org/ 10.1525/ae.2007.34.4.621.

Hersey, John B. 1965. "Sound Reflections in and under Oceans." Reprinted from Physics Today, (Nov): 17-24. John Brackett Hersey papers, MC-12, Box 16, Folder 2, Articles, abstracts reprints 1944-1982, Data Library and Archives, Woods Hole Oceanographic Institution, Woods, Hole, MA.

- - . 1971. "Speech Delivered in Annapolis June 23, 1971.” John Brackett Hersey Papers, MC-12, Box 16, Folder 1, Hersey, J. Brackett Speeches, 1955-1980, Data Library and Archives, Woods Hole Oceanographic Institution.

Hildebrand, John A. 2009. "Anthropogenic and Natural Sources of Ambient Noise in the Ocean." Marine Ecology Progress Series 395 (December): 5-20. https://doi.org/10.3354/meps08353.

ICOEES Typoe Task Group. 1968. "Executive Summary of Preliminary Position Paper, 'An International Decade of Ocean Exploration and Assessment of the Seas." Committee on Ocean Engineering. Rand (William W.) Papers ca. 1921-1968, SBHC Mss 46, Box 1, Department of Special Collections, Davidson, Library, University of California, Santa Barbara.

Ingold, Tim. 2002. The Perception of the Environment: Essays on Livelihood, Dwelling and Skill. New York: Routledge. https://doi.org/10.4324/9780203466025.

"IPOD Site Survey Criteria: Multichannel Seismic Surveys of IPOD Sites." 1975. In IPOD Site Survey Guidelines. Deep Earth Sampling Executive and Planning Committees, 1975-1976. College of Oceanic and Atmospheric Sciences Records, RG 173, Series II, Box 1, Oregon State University Special Collections and Archives Research Center, Corvallis, OR.

Iselin, Columbus O.'Donnell. 1932. “Some Phases of Modern Deep-Sea Oceanography.” In Annual Report of the Board of Regents of the Smithsonian Institution. Washington: United States Government Printing Office. http://library.si.edu/digital-library/book/annualreportofbo1932smit.

Jakosky, John J. et al. 1956. "Characteristics of Explosives for Marine Seismic Exploration." Geophysics 21 (4): 969-91. https://doi.org/10.1190/1.1438316.

Keevin, Thomas, and Gregory Hempen. 1997. "Environmental Effects of Underwater Explosions with Methods to Mitigate Impacts.” St. Louis: U.S. Army Corps of Engineers.

Knott, S.T., and E.T. Bunce. 1968. "Recent Improvement in Technique of Continuous Seismic Profiling.” Deep Sea Research 15 (5): 633-36. https://doi.org/10.1016/0011-7471(68)90072-7.

Koelsch, Donald E., Warren E. Sr. Witzell, James E. Broda, Frank B. Wooding, and G. M. Purdy. 1986. “A Deep Towed Explosive Source for Seismic Experiments on the Ocean Floor.” Marine Geophysical Researches 8 (4): 345-61. https://doi.org/10.1007/bf02084018.

LaFond, E.C., Robert S. Dietz, and J.A. Knauss. 1950. "A Sonic Device for Underwater Sediment Surveys." Journal of Sedimentary Petrology 20 (2): 107-10.

Larkin, Brian. 2008. Signal and Noise: Media, Infrastructure, and Urban Culture in Nigeria. Duke University Press. https://doi.org/10.2307/j.ctv1220mnp.

Lawrence, David M. 2002. Upheaval from the Abyss: Ocean Floor Mapping and the Earth Science Revolution. Kindle edition. Rutgers University Press.

Leenhardt, O. 2015. "Analysis of Continuous Seismic Profiles." The International Hydrographic Review 46 (1). https://journals.lib.unb.ca/index.php/ihr/article/view/23959. 
LeMenager, Stephanie. 2014. Living Oil: Petroleum Culture in the American Century. Oxford University Press. https://doi.org/10.1093/acprof:oso/9780199899425.001.0001.

Lemoult, Craig. 2019. "Researchers Worry Right Whales Could Be Harmed During Seismic Testing.” National Public Radio. https://www.npr.org/2019/04/15/713387959/researchers-worry-rightwhales-could-be-harmed-during-seismic-testing.

McCauley, Robert D., Ryan D. Day, Kerrie M. Swadling, Quinn P. Fitzgibbon, Reg A. Watson, and Jayson M. Semmens. 2017. "Widely Used Marine Seismic Survey Air Gun Operations Negatively Impact Zooplankton." Nature Ecology $\sigma^{2}$ Evolution 1 (0195). https://doi.org/10.1038/ s41559-017-0195.

Milburn, Colin. 2008. Nanovision. Durham: Duke University Press. https://doi.org/10.1515/ 9780822391487.

Natural Resources Defense Council. 2010. "Boom, Baby, Boom: The Environmental Impacts of Seismic Surveys," May 2010. https://www.nrdc.org/oceans/files/seismic.pdf.

- - . 2018. "In a Blow to Marine Life, Trump Administration Greenlights Seismic Blasting in Atlantic.” NRDC Expert Blog (blog). November 30, 2018. https://www.nrdc.org/experts/nrdc/ blow-marine-life-trump-administration-greenlights-seismic-blastingatlantic?fbclid=IwAR2VhjFA1GbXoi5IoGAeqahCoZJ3wXI1U4LgL7pgRJRw8Uou8lo0xadA29c.

- - . 2019. "Environmental Groups Ask Court to Block Harmful Seismic Blasting in the Atlantic,” February 20, 2019. https://www.nrdc.org/experts/nrdc/environmental-groups-askcourt-block-harmful-seismic-blasting-atlantic.

NOAA Fisheries. 2017. “Entanglement of Marine Life: Risks and Response.” NOAA, June 19, 2017. https://www.fisheries.noaa.gov/insight/entanglement-marine-life-risks-and-response.

NOAA National Marine Sanctuaries. 2016. “A Noisy Ocean: A Q\&A with Dr. Leila Hatch.” National Marine Sanctuaries, June 2016. https://sanctuaries.noaa.gov/news/jun16/noisyocean.html.

O'Brien, Joanne, Simon Berrow, and Dave Wall. 2005. "The Impact of Multibeam on Cetaceans: A Review of Best Practice." Irish Whale and Dolphin Group, March, 1-8. http://www.ecomarbelize.org/uploads/9/6/7/0/9670208/multibeam_1_.pdf.

Ocean Conservation Research. n.d. “Seismic Airgun Surveys.” http://ocr.org/portfolio/seismicairgun-surveys/.

O’Keefe, B. J. Correspondence to John B. Hersey. 1960, November 24, 1960. 1. John Brackett Hersey Papers, MC-12, Box 9, Folder 2, Hersey, J. Brockett Correspondence - Edgerton, Germeshausen \& Grier, Inc., 1960, Data Library and Archives, Woods Hole Oceanographic Institution. Woods Hole, MA. http://archives.mblwhoilibrary.org:8081/repositories/2/resources/17.

Peng, Chao, Xinguo Zhao, and Guangxu Liu. 2015. "Noise in the Sea and Its Impacts on Marine Organisms." International Journal of Environmental Research and Public Health 12 (10): 12304-23. https://doi.org/10.3390/ijerph121012304.

Propen, Amy. 2012. Locating Visual-Material Rhetorics: The Map, the Mill, and the GPS. Anderson: Parlor Press.

Rand, William Whitehall. 1957. "Santa Barbara Channel, Offshore Oil Exploration.” To Rotary Club. Rand (William W.) Papers ca. 1921-1968, SBHC Mss 46, Box 1, Department of Special Collections, Davidson Library, University of California, Santa Barbara.

Resolution of the Board of Supervisors of the County of Santa Barbara, \#8242. 1948.

Roberts, Eric. n.d. "Detonation and Combustion.” Stanford. https://cs.stanford.edu/people/ eroberts/courses/ww2/projects/firebombing/detonation-and-combustion.htm. 
Rosenberg, Amy. 2019. “'Torture for Marine Mammals': In Cape May, Trump Plan for Seismic Testing in Atlantic Ocean Is Panned.” The Philadelphia Inquirer, March 18, 2019. https://www.inquirer.com/news/new-jersey/trump-seismic-testing-oil-drilling-atlantic-ocean-newjersey-cape-may-rally-20190318.html.

Schor, Juliet B. 2010. Plenitude: The New Economics of True Wealth. New York: Penguin.

Serres, Michel. 1982. The Parasite. Translated by Lawrence R. Schehr. Baltimore: Johns Hopkins University Press.

Shiga, John. 2013. "Sonar: Empire, Media, and the Politics of Underwater Sound." Canadian Journal of Communication 38 (3): 357-77. https://doi.org/10.22230/cjc.2013v38n3a2664.

Sterne, Jonathan. 2003. The Audible Past. Cultural Origins of Sound Reproduction. Durham: Duke University Press. https://doi.org/10.1215/9780822384250.

Submarine Signal Company. 1932. "The Development of the Fathometer and Echo Depth Finding." Soundings. Columbus O'Donnell Iselin papers, 1904-1971, MC-16, Box 31, Folder 9, Data Library and Archives, Woods Hole Oceanographic Institution, Woods Hole, MA.

“Survey.” n.d. In . Merriam-Webster. Accessed July 17, 2019. https://www.merriam-webster.com/ dictionary/survey.

Szeman, Imre. 2007. "System Failure: Oil, Futurity, and the Anticipation of Disaster." South Atlantic Quarterly 106 (4): 805-23. https://doi.org/10.1215/00382876-2007-047.

Thompson, Emily Ann. 2004. The Soundscape of Modernity: Architectural Acoustics and the Culture of Listening in America, 1900-1933. Cambridge, MA: MIT Press.

Tursi, Frank. 2015. "A Very Brief History of Offshore Drilling." Coastal Review Online. https://www.coastalreview.org/2015/06/a-very-brief-history-of-offshore-drilling/.

United Geophysical Company. 1948. "Marine Seismograph Survey for Union Oil Company of California of 80\&81 Prospects, United Geophysical Co., Inc., 1-14.” William Whitehall Rand Papers. SBHC Mss 46. Department of Special Collections. Davidson Library. University of California, Santa Barbara.

Volmar, Axel. 2013. "Listening to the Cold War: The Nuclear Test Ban Negotiations, Seismology, and Psychoacoustics, 1958-1963.” Osiris 28 (1): 80-102. https://doi.org/10.1086/671364.

Weilgart, Lindy. 2013. "A Review of the Impacts of Seismic Airgun Surveys on Marine Life." Presented at the CBD Expert Workshop on Underwater Noise and its Impacts on Marine and Coastal Biodiversity, February 25-27, 2014, London, UK. https://www.cbd.int/ doc/?meeting=MCBEM-2014-01.

Westervelt, Bob. Correspondence to Robert A. Forsch. 1957, August 5, 1957. USNUSL, John Brackett Hersey Papers, MC-12, Box 9, Folder 2, Hersey J. Brackett Correspondence - U.S. Navy Underwater Sound Laboratory, 1948-1958, Data Library and Archives, Woods Hole Oceanographic Institution, Woods Hole, MA. http://archives.mblwhoilibrary.org:8081/ repositories/2/resources/17.

Yamato, Maya, and Nicholas D. Pyenson. 2015. "Early Development and Orientation of the Acoustic Funnel Provides Insight into the Evolution of Sound Reception Pathways in Cetaceans." Edited by Brian Lee Beatty. PloS One 10 (3): e0118582. https://doi.org/10.1371/journal.pone.0118582. 


\section{SUPPLEMENTARY MATERIALS}

Sound clip: Air gun and echo sounders.

Download: https://mediaenviron.org/article/21392-sonic-pipelines-at-the-seafloor/attachment/ 54741.mp4 